- The website provides as much information about the host city as it does about the meeting in an attempt to further attract delegates

- The contact person on the email is often presented as two given names, such as: Caroline Jennifer, Laura Jen, Elena Rose (I have indeed communicated with each of these 'names' to gather more information about their meetings)

- The initial approach is by email, describing the event as a 'Dental Congress, Global Summit, World Congress or International Conference

- The email, and other documents, contain multiple grammatical errors and the text is often nonsensical. An example being:

'It is our immense pleasure and honour to invite you as a keynote speaker for the 26th Euro Dentistry Congress at Amsterdam, Netherlands that is focused around the "Understanding and Recent Trends and Variations in Dentistry" as you have done your pioneering research in this area.

We are proud to say that we have successfully accomplished twenty-four events in this field, which were highly appreciated, and the gathering furnished us with lots of information, transformation of knowledge and ideas from different countries across the globe. However, the meetings were complemented, we feel a lot more ahead to be comprehended, motivate next generation, and help in advancing the field of Dentistry?

- The theme of the meeting is extremely vague, for example 'to present Innovative ideas and approaches for striving the future of Dental and Oral Health Care' or 'to Envision the On-Going Enhancements in the Field of Dentistry'

- The organiser is a name such as Science Access, EuroSciCon, Biocoreconferences, Allied Academies, Scientific Future or Scientific Federation rather than a society or association that is familiar to UK dentists and scientists
- The contact address is only a virtual mailing address for registered companies. In the UK these include 85 Great Portland Street, 47 Churchfield Road, 40, Bloomsbury Way (as well as a sandwich shop in Blyth, Northumberland)

- The clinical and scientific sessions cover almost every aspect of dentistry

- The organising committee comprises a vast number of individuals where the photographs and biographies have been copied from other websites

- The fee for a two-day meeting is around $€ 600-800$

- The list of speakers comprises names none of which you may have heard. It is always interesting to 'Google' speakers or even email them to ask politely whether they plan to attend

- The meetings (world conferences remember) are held in relatively small hotels and never in conference centres, colleges or universities.

\section{Concluding comments}

From my experience, the conferences that I have described are essentially small meetings, perhaps seminars would be a better term, based in hotel meeting rooms where delegates/ speakers present their research and are presented with a certificate of recognition for their contribution. There is an argument that suggests there is nothing untoward with such an event but if so then it should be advertised as such. The absence of peer-review to check the validity of research presentations is certainly a concern, but the use of names and photographs of speakers and organisers without their knowledge or permission for advertising purposes, and the construction of a website that clearly overplays the nature of the event is grossly misleading, bordering on deception. In the UK, we are fortunate in having numerous annual conferences, meetings and seminars that allow us to present our clinical acumen, expertise and research without the need to accept the invitations from predatory events.

Given my experience, I strongly recommend that all researchers and clinicians from all countries avoid these meetings and early career colleagues in particular should, if in any doubt, seek advice from supervisors and more senior colleagues as to the value of attending any conference. This advice also extends to colleagues who may be approached to serve on an organising committee or to give a presentation at a predatory conference. A colleague recounts:

'I was invited to speak at a conference in Rome and then, once I had agreed to speak, my invitation was extended to running a workshop. I was assured that 50 people had signed up for the workshop, only to find six attendees when I arrived at the hotel (the meeting venue) which was 45 minutes from Rome'!

1. Beall's list. Beall's List of Predatory Journals and Publishers. Available at https://beallslist.weebly.com/ (accessed January 2019)

2. Beall J. Dangerous predatory publishers threaten medica research.J Korean Med Sci 2016; 31:1511-1513.

3. Misra D P, Wakhlu A, Sharma A, Agarwal V, Negi V S. Publishing in black and white: the relevance of listing of scientific journals. Rheumatol Int 2017; 37: 1773-1778.

4. UCD Library. Predatory Publishers and Conferences. Available at https://libguides.ucd.ie/publishing/predatory (accessed January 2019).

5. International Family Nursing Association. What is a pred atory conference? Available at https://internationalfamilynursing.org/wordpress/wp-content/uploads/2016/02/ IFNA.What-is-a-predatory-conference.pdf (accessed January 2019)

6. Spears, T. When pigs fly: Fake science conferences abound for fraud and profit. Ottawa Citizen (Ottawa) 2017 March 12.

7. BDORT. Bi-Digital O-Ring Test. Available at http://bdort. org/ (accessed January 2019).

\title{
Correction
}

Research Article Br Dent J 2018; 225: 953-956.

Trends in referral format and dental notation used in primary care referrals to dental specialists

When this article was initially published Table 1 incorrectly stated that in the Universal system the upper left first permanent molar is written as 16. In the Universal system the upper left first permanent molar is actually written as 14 .

The author apologises for any confusion caused by this error. 